\title{
SOLID DOSAGE FORM DEVELOPMENT OF GLIBENCLAMIDE WITH INCREASING THE SOLUBILITY AND DISSOLUTION RATE USING COCRYSTALLIZATION
}

\author{
ARIF BUDIMAN ${ }^{*}$, SANDRA MEGANTARABb, PUTRI RARASWATIa, TAZYINUL QORIAH A. ${ }^{a}$
}

aDepartment of Pharmaceutic and Technology of Pharmacy, Faculty of Pharmacy, Universitas Padjadjaran, bDepartment of Pharmaceutical Analysis and Medicinal Chemistry, Faculty of Pharmacy, Universitas Padjadjaran

Email: arif.budiman@unpad.ac.id

Received: 21 Aug 2018, Revised and Accepted: 12 Sep 2018

\section{ABSTRACT}

Objective: The aim of this study was to develop a solid dosage form of glibenclamide with increasing the solubility properties of glibenclamide with cocrystallization method.

Methods: Virtual screening was performed to investigate the interaction between glibenclamide and a co-former. Saccharin, the selected co-former, then co-crystallized with glibenclamide with equimolar ratios of 1:1 and 1:2 using the solvent evaporation method. Further characterization was performed using an infra-red (IR) spectrophotometer, differential scanning calorimetry (DSC), and powder x-ray diffraction (PXRD).

Results: Co-crystals of 1:2 equimolar ratio were more highly soluble compared to pure glibenclamide (30-fold for $12 \mathrm{~h}$ and 24 -fold for $24 \mathrm{~h}$ ). The dissolution rate had also increased from $46.838 \%$ of pure glibenclamide to $77.655 \%$ of glibenclamide co-crystal in 60 min. There was no chemical reaction observed during the co-crystallization process based on the IR spectrum. However, there was a new peak in the X-Ray diffractogram and a reduction of melting point in the DSC curve, indicating the formation of co-crystals.

Conclusion: The optimal co-crystal ratio of glibenclamide-saccharin was found to be $1: 2$, which was successful in improving the solubility of glibenclamide.

Keywords: Glibenclamide, Co-crystal, Saccharin, Dissolution

(C) 2018 The Authors. Published by Innovare Academic Sciences Pvt Ltd. This is an open-access article under the CC BY license (http://creativecommons.org/licenses/by/4.0/) DOI: http://dx.doi.org/10.22159/ijap.2018v10i6.29257

\section{INTRODUCTION}

Oral preparation is the easiest and most widely used drug delivery route because it has several advantages, namely ease of administration, high level of patient compliance, cost-effective, and tends to be flexible in terms of dosage formulations. However, the biggest challenge in designing oral dosage form is low bioavailability property. Bioavailability is influenced by several factors, including water solubility, drug permeability, dissolution rate, first-pass metabolism, and pre-systemic metabolism. The most common causes of low bioavailability are low solubility and permeability $[1,2]$.

Today, nearly $40 \%$ of pharmaceutical preparations on the market have low solubility based on the biopharmaceutical classification system (BCS). It is estimated that $90 \%$ of drugs that currently being developed are classified to poor-soluble drugs [3]. In the past, the industry consensus thought that those candidates was highly risk in drug development. However, because of the large number of them, the industry consensus also changed the point of view of the drugs from avoidance to acceptance as the dedication of the research provided to solve the challenges regarding the solubility $[4,5]$.

In dealing with this problem, the pharmaceutical industry has developed several methods to improve drug solubility. These methods include salt formation [6], co-crystal [7], self-emulsifying drug delivery systems (SEEDS) [8], cyclodextrin [9], pH-microenvironmental modifiers [10], solid lipid nanoparticles [11], micelles [12], high energy polymorphs [13], soft gelatin capsules [14], and liposomes [15]. Co-crystallization method and salt formation have several advantages in physicochemical properties and are able to improve the parent drug without changing therapeutic efficiency [7]. Traditionally, the formation of salt is more widely used by researchers in the medicinal and synthetic chemistry field by using bases or weak acids [6]. However, only $20-30 \%$ of the new molecules can form salt spontaneously, so that $70-80 \%$ of the remaining molecules must be given via different routes to increase solubility [16]. Another simple method to improve solubility is cocrystallization. Co-crystallization method is a method of co-crystal formation by adding co-former into active pharmaceutical ingredients in order to increase solubility without affecting its pharmacological activity [17]. Formation of co-crystal is better in reducing unintended property of the parent substance [18].

The previous study showed that co-crystallization method can increase the solubility of simvastatin 2-fold from pure simvastatin with malic acid as the co-former [19]. Bencoic acid and aspartam also could be used as co-former in improving atorvastatin solubility by the co-crystallization method, from $22.08 \mathrm{ppm}$ to $28.91 \mathrm{ppm}$ and $30.20 \mathrm{ppm}$, respectively [20]. In this study, the co-crystal of glibenclamide-saccharin were prepared with the equimolar ratio is $1: 1$ and $1: 2$. Saccharin is the excipient that easily accessible and has an affordable price. As a co-former, saccharin could increase ketoprofen solubility up to $30 \%$ [21].

\section{MATERIALS AND METHODS}

\section{Materials}

Glibenclamide was obtained from PT. Indofarma Tbk, Bekasi, Indonesia. Saccharin, methanol, potassium dihydrogen phosphate, and potassium hydrogen phosphate were purchased from Merck, Germany. All reagents used were analytical grade.

\section{Methods}

\section{Virtual screening}

The virtual screening method was used to predict the bond formed between glibenclamide and its co-former. The expected bonds were hydrogen, van der Waals, and $\pi-\pi$ bonds. The $2 \mathrm{D}$ structure of the active pharmaceutical ingredients and co-former was prepared using ChemBioDraw Ultra 12.0 (trial version) and converted into. cdx format. The 2D structure was converted into a 3D structure using ChemBio3D Ultra 12.0 (trial version) by the mechanical method (Hartree-Fock, set $321 \mathrm{G}$ ), and the file was saved as a. pdb format. Molecular docking of active pharmaceutical ingredients was performed using PyRx-Virtual Screening Tools (trial version) with AutoDock Vina as the engine. The molecular docking results were analyzed based on binding affinity value, type, and the position of 
bonds formed between glibenclamide and the co-former using AutoDock Tools-1.5.6rc3 (trial version) [22].

\section{Preparation of glibenclamide co-crystal using solvent evaporation method}

Glibenclamide and saccharin were weighed in accordance with equimolar ratios of 1:1 and 1:2. Each mixture was dissolved in methanol homogenously and evaporated in a water bath at $45^{\circ} \mathrm{C}$ for $24 \mathrm{~h}$ or until the methanol completely evaporated. The co-crystal obtained was stored in a desiccator and further analyzed for characterization and evaluation [22].

\section{Optimization of $\mathrm{pH}$ of glibenclamide dissolution medium}

Buffer phosphate solution (BPS) was used as the dissolution medium and prepared with various $\mathrm{pH}(6.4 ; 7.6$; 8.0) for $900 \mathrm{ml}$. Dissolution test of standard glibenclamide was performed using type 2 apparatus (paddle) at $75 \mathrm{rpm}$ for $60 \mathrm{~min}\left(37 \pm 0.2^{\circ} \mathrm{C}\right)$. At predetermined interval times $(5 ; 10 ; 15 ; 30 ; 45 ; 60 \mathrm{~min}), 5 \mathrm{ml}$ of sample was taken and then replaced by fresh medium. The aliquot sample was analyzed using a UV Spectrophotometer (analytical Jena, specord $200 \AA$ ) to quantify the amount of dissolved glibenclamide concentration and the optimum $\mathrm{pH}$ of the medium [23].

\section{Determination of solubility}

Each co-crystal of glibenclamide was weighed equivalently to $20 \mathrm{mg}$ glibenclamide then put into $20 \mathrm{ml}$ distilled water and shaken for 12 and $24 \mathrm{~h}$ using a mechanical agitator (IKA HS 260 basic $®$ ) at $120 \mathrm{rpm}$ at room temperature. After shaking, the solution was filtered and diluted into $100 \mathrm{ppm}$ using methanol. Each sample was analyzed using a UV-Vis Spectrophotometer (analytical Jena, specord 200®) [24].

\section{Dissolution test}

Dissolution test of glibenclamide was performed using type 2 apparatus (paddle) at $75 \mathrm{rpm}$ for $60 \mathrm{~min}\left(37 \pm 0.2^{\circ} \mathrm{C}\right)$. The medium was BPS (pH 8.0) $900 \mathrm{ml}$. At predetermined interval times $(5 ; 10$; $15 ; 30 ; 45 ; 60 \mathrm{~min}), 5 \mathrm{ml}$ of sample was taken and then equally replaced by fresh medium. The aliquot sample was analyzed using a
UV Spectrophotometer (analytical Jena, specord $200 \circledast$ ) to quantify the amount of dissolved glibenclamide concentration [23].

\section{Characterization}

\section{Infrared spectrophotometry}

$1 \mathrm{mg}$ of Co-crystal of glibenclamide was carefully weighed and homogeneously mixed with $250 \mathrm{mg}$ of $\mathrm{KBr}$. The mixture was compressed at 80 Psi to obtain a pellet. The pellet was analyzed using an infrared spectrophotometer (Shimadzuß) at room temperature in a range of wavenumbers from $400-4000 \mathrm{~cm}^{-1}$. The $\mathrm{KBr}$ pellet was used as a blank [25].

\section{Powder X-ray diffraction (PXRD)}

PXRD measurements were conducted using Phillip PW 1835 under the following conditions: target, $\mathrm{Cu}$; voltage, $40 \mathrm{kV}$; and current, $40 \mathrm{~mA}$. The scans were performed with a detector step size of $0.02^{\circ}$ over an angular range of $2 \theta=2-50{ }^{\circ} \mathrm{C}$ [26].

\section{Differential scanning calorimetry (DSC)}

DSC analysis was performed usingLinseis DSC PT1000, which was periodically calibrated using indium. Approximately $4 \mathrm{mg}$ of the powder sample was placed in an aluminum pan with a pinhole for the measurement. Dry nitrogen was used as the inert gas at a flow rate of $30 \mathrm{ml} / \mathrm{min}$, and the measurements were carried out at 50 $300{ }^{\circ} \mathrm{C}$ at a heating rate of $10^{\circ} \mathrm{C} / \mathrm{min}[26]$.

\section{RESULTS AND DISCUSSION}

\section{Virtual screnning of glibenclamide co-crystal}

Virtual screening was performed using molecular modelling and the molecular docking program to predict the bonds formed when combining glibenclamide and the co-former structure. Virtual screening was used to determine which co-former should be used in later steps [27]. Molecular docking was used to determine that the selected parameter of the co-former had a high number of hydrogen bonds and a small value of energy of interaction (Ei); the smaller the Ei, the stronger the bond [20].

Table 1: The result of the virtual screening of glibenclamide-saccharin

\begin{tabular}{llll}
\hline Co-former & 2D-structure & Ei (kca/mol) \\
\hline Saccharin & Interaction & 1.4 .467 \\
$2 .-3.951$
\end{tabular}

The virtual screening results showed that two interactions were observed. Hydrogen bonds were formed from hydrogen atoms of the amide groups of glibenclamide and oxygen atoms of sulfonyl of saccharin (table 1). In addition, $\pi-\pi$ and van der Waals bonds could also be used as a selection parameter of the co-former. However, $\pi-\pi$ bonds have lower electronegativity than hydrogen bonds, and van der Waals bonds are weaker than hydrogen bonds $[28,21]$. Covalent bonds are undesirable because they are immensely strong, will bind irreversibly to the body, and may cause toxicity [29].

\section{Preparation of glibenclamide co-crystal}

Slow solvent evaporation and grinding are widely used cocrystallization methods, thus the common principles in the cocrystallization process were solvent-based and grinding. Therefore, the co-crystallization process of glibenclamide-saccharin was performed using the basic solvent evaporation method, as the objective was to attain solubilization and slow evaporation. While the solvent evaporated, the molecules in the solution reacted and formed hydrogen bonds. Thus, an advantage of this method was that the optimal co-crystal obtained might improve the solubility of the active pharmaceutical ingredient [30]. Co-crystallization using the equimolar ratio of each component was appropriate in the solvent evaporation method because, with the stoichiometry ratio, the possibility of generating intermolecular bonds is high [31].

\section{Determination of solubility}

In this study, the determination of solubility of the glibenclamide cocrystal was performed based on the Higuchi and Connor method, which consists of five steps to determining the solubility of a compound: sample preparation, equilibration, separation, sample analysis, and data analysis [24].

The solubility of glibenclamide-saccharin (1:2) was higher than the solubility of its pure form and glibenclamide-saccharin (1:1) (fig. 1). The higher content of the co-former led to the improvement of solubility because the co-former can reduce barriers of the 
compound, thus making the solubilization process easier [32]. In this study, saccharin as a co-former was capable of reducing the barrier because it was highly soluble in water and then ionized; thus, the drug was solubilized easier [33].

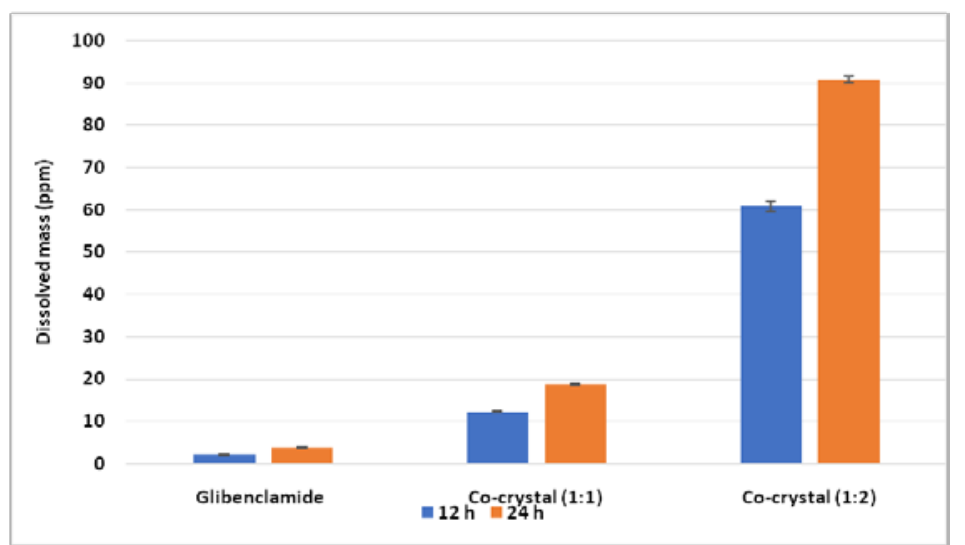

Fig. 1: Solubility of glibenclamide co-crystal for 12 and $24 \mathrm{~h}$ (All the values were calculated as mean \pm standard deviation; $\mathrm{n}=3$ )

\section{Dissolution test}

The dissolution test was performed on the co-crystal with the best equimolar ratio based on the solubility test i.e., glibenclamidesaccharin 1:2 compared with pure glibenclamide. Optimization of
$\mathrm{pH}$ of dissolution medium was performed at $\mathrm{pH} 6.4,7.6$, and 8.0. In table 4 , the concentration of standard glibenclamide $60 \mathrm{~min}$ was $9.91,16.43$, and $45.31 \mathrm{ppm}$ for $\mathrm{pH} 6.4,7.6$, and 8.0 , respectively. Based on the results, 8.0 was the optimum $\mathrm{pH}$ for the dissolution test of glibenclamide.

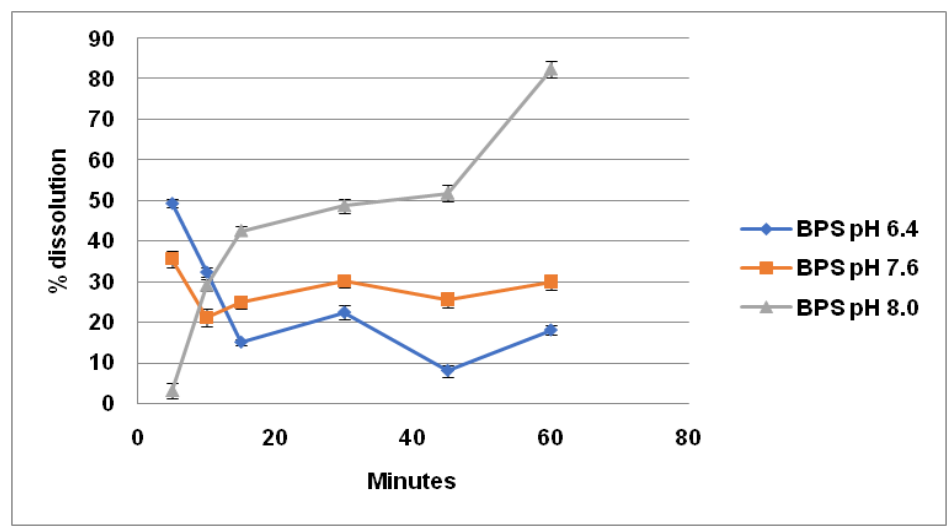

Fig. 2: Optimization of $\mathrm{pH}$ of dissolution medium (All the values were calculated as mean \pm standard deviation; $\mathbf{n}=3$ )

In fig. 2, the dissolution rate of co-crystal of glibenclamidesaccharin was higher than its pure form. As stated in the literature, glibenclamideonly dissolved $45 \%$ in $60 \mathrm{~min}$. In this study, pure glibenclamide dissolved $46.83 \%$ in 60 min [34]. However, the cocrystal of glibenclamide-saccharin (1:2) dissolved $77.65 \%$ in 60 $\min$.

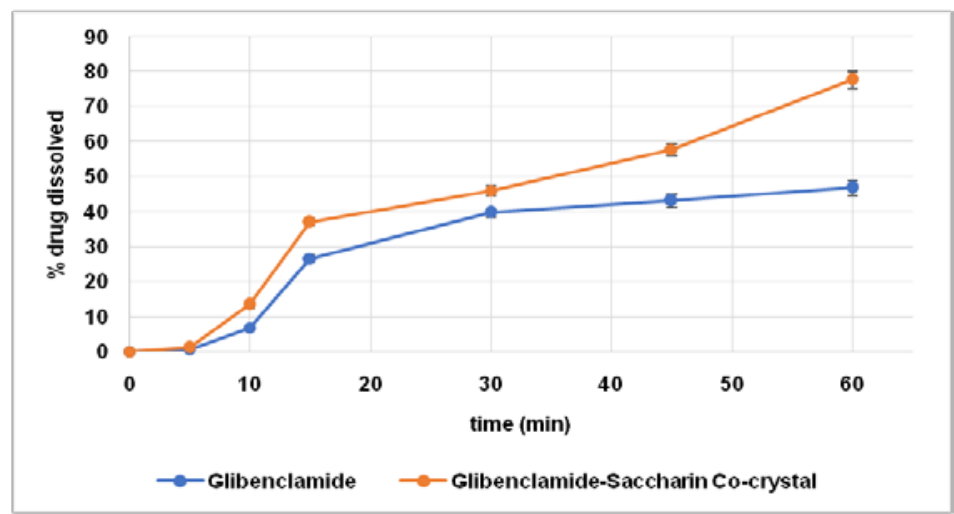

Fig. 3: Result of dissolution test of pure glibenclamide (blue line) and glibenclamide-saccharin (red line) (All the values were calculated as mean \pm standard deviation; $n=3$ ) 


\section{Characterization}

Characterization of the co-crystal was performed on glibenclamidesaccharin (1:2) and its pure form. The aim of characterization was to determine the characteristics of the co-crystal and compare it with pure glibenclamide.

\section{Infrared spectrophotometry}

In fig. 3, the peaks of pure glibenclamide were $33367.71 \mathrm{~cm}^{-1}$ and $3313.71 \mathrm{~cm}^{-1}$ (N-H Stretch), $3116.97 \mathrm{~cm}^{-1}$ (O-H Stretch), $2931.80 \mathrm{~cm}^{-1}$, and $2854.65 \mathrm{~cm}^{-1}$ (C-H Stretch), $1716.65 \mathrm{~cm}^{-1}$ (C=0 Stretch) and 1616.35 $\mathrm{cm}^{-1}\left(\mathrm{C}=\mathrm{C}\right.$ Stretch). The peaks of pure saccharin were $3398.57 \mathrm{~cm}^{-1}(\mathrm{~N}-\mathrm{H}$ Stretch), $3093.82 \mathrm{~cm}^{-1}$ (O-H Stretch), $2974.23 \mathrm{~cm}^{-1}$ (C-H Stretch) and
$1724.3665 \mathrm{~cm}^{-1}$ (C=0 Stretch). The peaks of the co-crystal of glibenclamide-saccharin were $3367.71 \mathrm{~cm}^{-1}$ and $3313.71 \mathrm{~cm}^{-1}(\mathrm{~N}-\mathrm{H}$ Stretch), $3093.82 \mathrm{~cm}^{-1}$ (O-H Stretch), $2931.80 \mathrm{~cm}^{-1}$ and 2854,65 cm-1 (C-H Stretch), $1616.35 \mathrm{~cm}^{-1}(\mathrm{C}=\mathrm{C}$ Stretch $)$ and $1720.50 \mathrm{~cm}^{-1}(\mathrm{C}=0$ Stretch $)$. The $\mathrm{C}=0$ peak was weakened from $1716.65 \mathrm{~cm}^{-1}$ to $1720.50 \mathrm{~cm}^{-1}$, indicating that there was a formation of hydrogen bonds marked by a bond on the extended of $\mathrm{C}=\mathrm{O}$ group, which reduced the bond strength. Compared to the functional group of glibenclamide-saccharin and its components (glibenclamide and saccharin), no new peaks were observed, indicating that no additional functional group was formed and no chemical reaction occurred during co-crystal preparation. However, the peaks of 2009.83 $\mathrm{cm}^{-1}, 1975.11 \mathrm{~cm}^{-1}$, and $1863.24 \mathrm{~cm}^{-1}$ in the glibenclamide-saccharin spectrum were from the saccharin peaks.

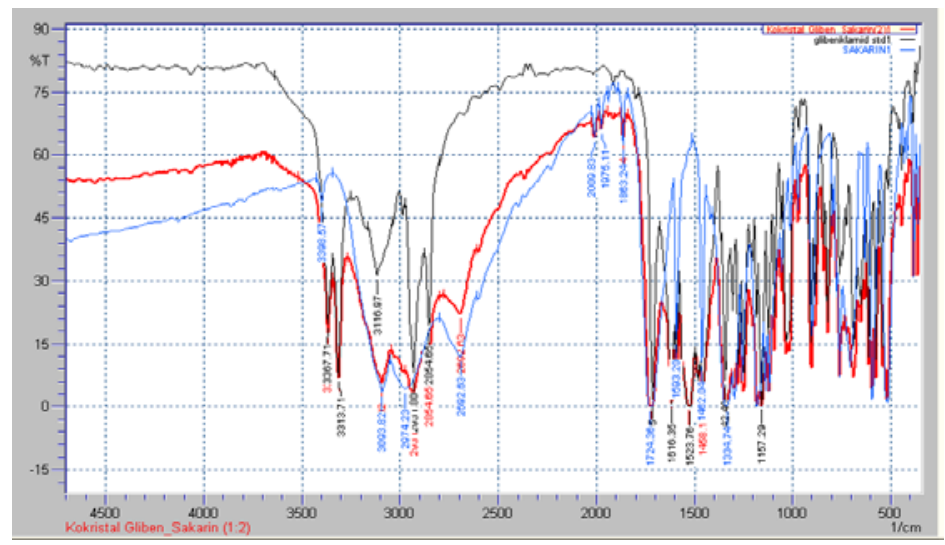

Fig. 4: Infrared spectrum of pure glibenclamide (black line), saccharin (blue line), and glibenclamide-saccharin (red line)

\section{Powder X-ray diffraction (PXRD)}

In fig. 4 , the intensity of the glibenclamide-saccharin (1:2) diffractogram was higher than glibenclamide and saccharin. Pure glibenclamide was semi-crystalline, but both saccharin and glibenclamide-saccharin were crystalline. The highest intensity of glibenclamide-saccharin $(1: 2)$ was $100 \%$ at $2 \theta$ of $15.79{ }^{\circ}$. Peak amounts of pure glibenclamide and glibenclamide-saccharin were different, at 40 and 44 peaks, respectively.

These differences indicate that there was a difference in the structure due to the co-crystal formation $[35,36]$.

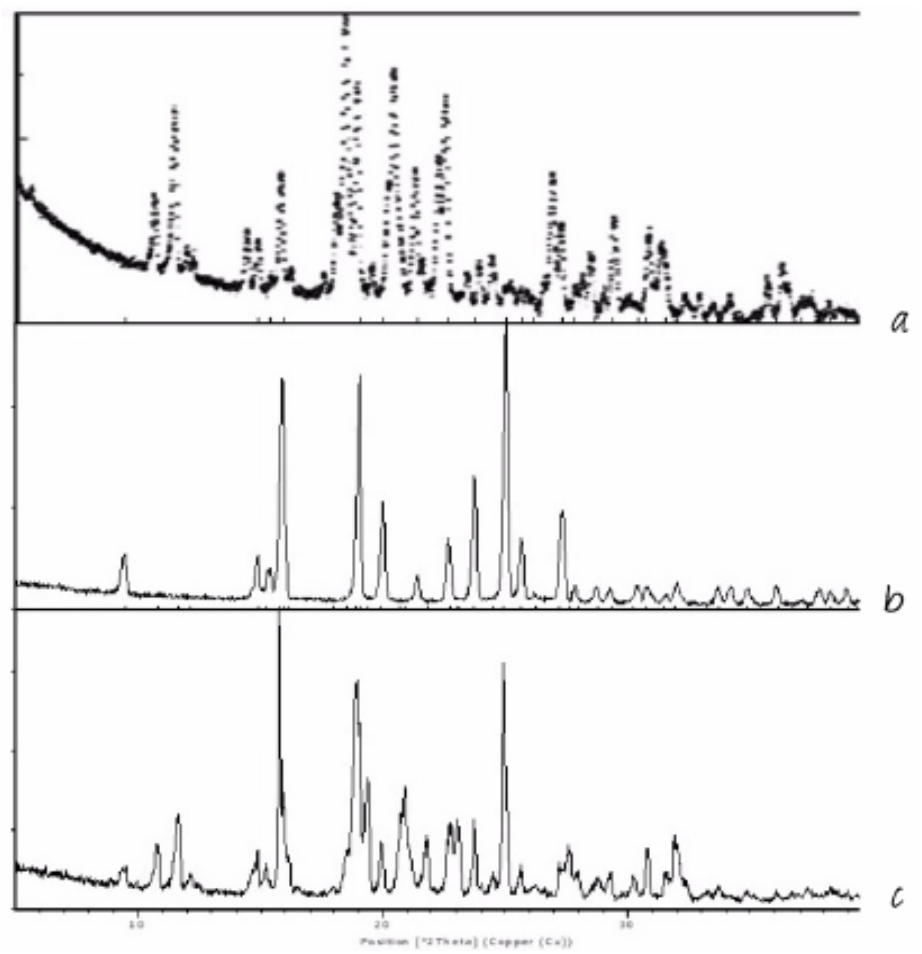

Fig. 5: Diffraction of glibenclamide (a), saccharain (b), and glibenclamide-saccharin (1:2) (c) 
Table 2: The result of PXRD

\begin{tabular}{llll}
\hline $\mathbf{2 \theta}\left({ }^{\circ}\right)$ & Intensity & & \\
\cline { 2 - 4 } & Glibenclamide & Saccharin & Glibenclamide-saccharin (1:2) \\
\hline 15.79 & 11.30 & 10.68 & 100 \\
24.93 & 10 & 44 & 83.02 \\
\hline
\end{tabular}

\section{Differential scanning calorimetry (DSC)}

Differential scanning calorimetry (DSC) is an analytical instrument used in characterization to determine the solid-state interaction of two compounds or more by giving heat energy to the co-crystals to evaluate thermodynamic changes (endothermic or exothermic peaks) [37] Changes were noted in the thermodynamic aspects of the solid as well as in the shape of the solid crystalline structure due to the physical interaction by the thermal analysis of two compounds or more [25]

The thermogram of glibenclamide, saccharin, and glibenclamidesaccharin can be seen in fig. 5 and table 6. In the thermogram, there was an endotherm peak of pure glibenclamide at $174.66{ }^{\circ} \mathrm{C}$, indicating the melting point of glibenclamide, and $259.89{ }^{\circ} \mathrm{C}$, indicating the decomposition of glibenclamide. The endotherm peak of saccharin was at $229.06^{\circ} \mathrm{C}$, indicating that saccharin did not have a melting point but started to degrade after reaching said temperature. The glibenclamide-saccharin melting point was lower than those of glibenclamide and saccharin alone, at $157.87{ }^{\circ} \mathrm{C}$. Compared to solubility properties, it is reasonable to conclude that glibenclamide-saccharin has a higher solubility than pure glibenclamide. According to the literature, the co-crystallization process results in a change of the melting point of the compound compared to its components, as a co-crystal melting point is typically lower than those of its components [22,37].

Table 5: The result of DSC analysis

\begin{tabular}{|c|c|c|c|}
\hline \multirow[t]{2}{*}{ Sample } & \multicolumn{3}{|c|}{ Melting point $\left({ }^{\circ} \mathrm{C}\right)$} \\
\hline & Onset & Peak & Endset \\
\hline Glibenclamide & 171.96 & 174.66 & 178.33 \\
\hline Saccharin & 225.65 & 229.06 & 233.61 \\
\hline Glibenclamide-saccharin & 145.60 & 157.87 & 170.69 \\
\hline
\end{tabular}

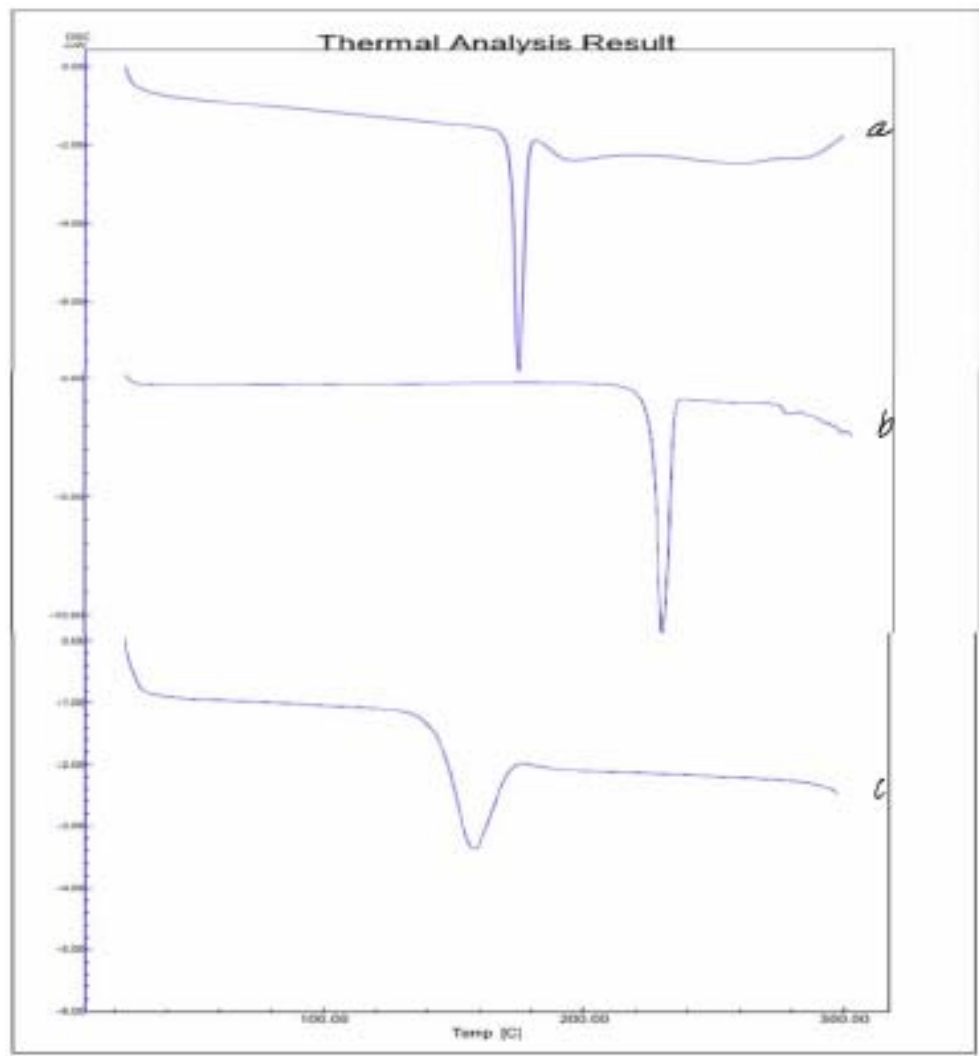

Fig. 6: DSC thermogram of (a) glibenclamide, (b) saccharin, and (c) glibenclamide-saccharin (1:2)

\section{CONCLUSION}

The co-crystallization method was successful in improving the solubility of glibenclamide using saccharin as the co-former with an optimal equimolar ratio of $1: 2$. The dissolution rate also increased from $46.838 \%$ of pure glibenclamide to $77.655 \%$ of glibenclamide co-crystal in $60 \mathrm{~min}$. There was no chemical interaction observed based on the infrared spectrum, but the co-crystal was successfully formed based on the diffractogram and thermogram.

\section{ACKNOWLEDGMENT}

The authors thanks to UniversitasPadjadjaran for financial support in this research with scheme Riset Fundamental Unpad 2018. 


\section{CONFLICTS OF INTERESTS}

All authors have none to declare

\section{AUTHORS CONTRIBUTIONS}

All the authors have contributed equally

\section{REFERENCES}

1. Tian S, Li Y, Wang J, Zhang J, Hou T. ADME evaluation in drug discovery. 9. Prediction of oral bioavailability in humans based on molecular properties and structural fingerprints. Mol Pharm 2011;8:841-51.

2. Rehder SC. Solid-state transformations induced by pharmaceutical processes during manufacturing; 2013.

3. Loftsson T, Brewster ME. Pharmaceutical applications of cyclodextrins: basic science and product development. J Pharm Pharmacol 2010;62:1607-21.

4. Kipp JE. The role of solid nanoparticle technology in the parenteral delivery of poorly water-soluble drugs. Int J Pharm 2004;284:109-22.

5. Singh A, Worku ZA, Van den Mooter G. Oral formulation strategies to improve solubility of poorly water-soluble drugs. Expert Opin Drug Delivery 2011;8:1361-78.

6. Serajuddin ATM. Salt formation to improve drug solubility. Adv Drug Delivery Rev 2007;59:603-16.

7. Schultheiss N, Newman A. Pharmaceutical cocrystals and their physicochemical properties. Cryst Growth Des 2009;9:2950-67.

8. Gursoy RN, Benita S. Self-emulsifying drug delivery systems (SEDDS) for improved oral delivery of lipophilic drugs. Biomed Pharmacother 2004;58:173-82.

9. Stella VJ, He Q. Cyclodextrins. Toxicol Pathol 2008;36:30-42.

10. Stephenson GA, Aburub A, Woods TA. Physical stability of salts of weak bases in the solid -stateJ Pharm Sci 2011;100:1607-17.

11. Muchow M, Maincent $P$, Müller RH. Lipid nanoparticles with a solid matrix (SLN®, NLC®, LDC®) for oral drug delivery. Drug Dev Ind Pharm 2008;34:1394-405.

12. Letchford $\mathrm{K}$, Burt $\mathrm{H}$. A review of the formation and classification of amphiphilic block copolymer nanoparticulate structures: micelles, nanospheres, nanocapsules and polymersomes. Eur J Pharm Biopharm 2007;65:259-69.

13. Singhal D, Curatolo W. Drug polymorphism and dosage form design: a practical perspective. Adv Drug Delivery Rev 2004;56:335-47.

14. Gullapalli RP. Soft gelatin capsules (softgels). J Pharm Sci 2010;99:4107-48.

15. Fenske DB, Chonn A, Cullis PR. Liposomal nanomedicines: an emerging field. Toxicol Pathol 2008;36:21-9.

16. Jermain SV, Brough C, Williams RO. Amorphous solid dispersions and nanocrystal technologies for poorly water-soluble drug delivery-an update. Int J Pharm 2018;535:379-92.

17. He G, Jacob C, Guo L, Chow PS, Tan RBH. Screening for cocrystallization tendency: the role of intermolecular interactions. J Phys Chem B 2008;112:9890-5.

18. Samie A, Desiraju GR, Banik M. Salts and cocrystals of the antidiabetic drugs gliclazide, tolbutamide, and glipizide: solubility enhancements through drug-coformer interactions. Cryst Growth Des 2017;17:2406-17.

19. Sopyan, I, Fudholi A, Muchtaridi M, Puspitasari I. A novel of cocrystalization, to improve solubility and dissolution rate of simvastatin. Int J PharmTech Res 2016;9:483-91.

20. Gozali D, Megantara S, Levita J, Bahti HH, Soewandhi SN, Abdassah M. Virtual screening of coformers for atorvastatin cocrystallization and the characterizations of the co-crystals. Int J Pharm Sci Res 2016;7:1450-5.

21. Siswandi S, Rusdiana T, Levita J. Virtual screening of coformers for ketoprofen co-crystallization and the molecular properties of the co-crystal. J Appl Pharm Sci 2015;5:78-82.

22. Qiao N, Li M, Schlindwein W, Malek N, Davies A, Trappitt G. Pharmaceutical cocrystals: an overview. Int J Pharm 2011; 419:1-11.

23. Gianotto EA dos S, Arantes RP, Lara-Filho MJ, Casimiro Filho ACS, Fregonezi-Nery MM. Dissolution test for glibenclamide tablets. Quim Nova 2007;30:1218-21.

24. Jouyban A. Handbook of solubility data for pharmaceuticals. CRC Press; 2009.

25. Purwantoro DU, Nugrahani I, Surantaatmadja SI. Studies of preparation, characterization, and solubility of mefenamic acidnicotinamide co-crystal synthesized by using melt crystallization method. Asian J Pharm Clin Res 2017;10:135-9.

26. Machiste EO, Giunchedi P, Setti M, Conte U. Characterization of carbamazepine in systems containing a dissolution rate enhancer. Int J Pharm 1995;126:65-72.

27. Musumeci D, Hunter CA, Prohens R, Scuderi S, McCabe JF. Virtual cocrystal screening. Chem Sci 2011;2:883-90.

28. Melandri S. Union is a strength: how weak hydrogen bonds become stronger. Phys Chem Chem Phys 2011;13:13901-11.

29. Arunan E, Desiraju GR, Klein RA, Sadlej J, Scheiner S, Alkorta I, et al. Definition of the hydrogen bond (IUPAC Recommendations 2011). Pure Appl Chem 2011;83:1637-41.

30. Jayasankar A, Somwangthanaroj A, Shao ZJ, Rodríguez-Hornedo N. Cocrystal formation during cogrinding and storage is mediated by amorphous phase. Pharm Res 2006;23:2381-92.

31. Vishweshwar P, McMahon JA, Bis JA, Zaworotko MJ. Pharmaceutical co-crystals. J Pharm Sci 2006;95:499-516.

32. Wouters J, Quere L. Pharmaceutical salts and co-crystals. Royal Soc Chem; 2011. p. 391.

33. Rodriguez Hornedo N, Nehm SJ, Jayasankar A. Cocrystals: design, properties and formation mechanisms. In: Swarbrick J. editor. Encycl. Pharm. Technol. Vol. 1. 3rd editio. New York: Informa Healthcare USA, Inc.; 2007. p. 615-35.

34. Patel PA, Chaulang GM, Akolkotkar A, Mutha SS, Hardikar SR, Bhosale AV. Self emulsifying drug delivery system: a review. Res J Pharm Technol 2008;1:313-23.

35. Ivanisevic I, McClurg RB, Schields PJ. Uses of X-ray powder diffraction in the pharmaceutical industry. In: Gad SC. editor. Pharm Sci Encycl 2010. Doi:10.1002/9780470571224.pse414.

36. Prohens Lopez R, Puigjaner Vallet MC. Crystal engineering studies: polymorphs and co-crystals. Handb Instrum Tech Mater Chem Biosci Res Barcelona: Centres Científics i Tecnològics. Universitat de Barcelona; 2012.

37. Raghuram M, Alam MS, Prasad M, Khanduri CH. Pharmaceutical cocrystal of prulifloxacin with nicotinamide. Int J Pharm Pharm Sci 2014;6:180-4. 